\title{
Melanoma-associated antigen expression and the efficacy of tyrosine kinase inhibitors in head and neck cancer
}

\author{
STEFAN HARTMANN, ROMAN C. BRANDS, NORA KÜCHLER, ANDREAS FUCHS, CHRISTIAN LINZ, \\ ALEXANDER C. KÜBLER and URS D.A. MÜLLER-RICHTER
}

\begin{abstract}
Department of Oral and Maxillofacial Plastic Surgery, University Hospital of Würzburg, Würzburg, Franconia D-97070, Germany
\end{abstract}

Received November 4, 2014; Accepted May 26, 2015

DOI: $10.3892 / 01.2015 .3345$

\begin{abstract}
Melanoma-associated antigen (MAGE) has been identified in a variety of types of cancer. The expression of several MAGE subgroups is correlated with poor prognosis and chemotherapeutic resistance. One target of chemotherapeutic treatment in head and neck cancer is the epidermal growth factor receptor (EGFR). The efficacy of tyrosine kinase inhibitors (TKI) in the context of melanoma-associated antigens is discussed in the present study. Five human squamous cell carcinoma cell lines were treated with the EGFR TKIs, erlotinib and gefitinib. The efficacy of these agents was measured using a crystal violet assay. Furthermore, the expression levels of MAGE-A1, -A5, -A8, -A9, -A11 and -A12 were determined by reverse transcription-quantitative polymerase chain reaction. The association between TKI efficacy and MAGE-A expression was analyzed by linear regression. The cell lines revealed inhomogeneous expression patterns for the MAGE-A subgroups. Four of the five cell lines demonstrated a good response to erlotinib and gefitinib. However, treatment with erlotinib induced better results than those of gefitinib, and revealed a concentration-dependent effect. The expression of MAGE-A5 and -A11 were significantly correlated with lower efficacy of erlotinib and gefitinib. By contrast, MAGE-A12 was associated with a superior response to these two drugs. One cell line, which expressed all investigated MAGE-A subgroups, was entirely resistant to the two TKIs. These results revealed a notable correlation between MAGE-A5 and -A11 and lower efficacy of EGFR TKIs. Pretreatment analysis of MAGE-A status may therefore aid improvement of chemoprevention using erlotinib and gefitinib in head and neck cancer.
\end{abstract}

Correspondence to: Dr Stefan Hartmann, Department of Oral and Maxillofacial Plastic Surgery, University Hospital of Würzburg, 2 Pleicherwall, Würzburg, Franconia D-97070, Germany

E-mail: hartmann_s2@ukw.de

Key words: melanoma-associated antigen-A, erlotinib, gefitinib, tumor antigen, epidermal growth factor receptor

\section{Introduction}

Over 20 years ago, the melanoma-associated antigens (MAGEs) were identified by van der Bruggen et al (1). MAGEs belong to the group of cancer/testis antigens (CTA), which includes multiple proteins, for example NY-ESO-1, sinovial sarcoma X and $\mathrm{G}$ antigen 1 (2). It is known that these proteins are found in adult male germ cells, fetal keratinocytes, the placenta and a variety of human malignancies, including head and neck cancer (3-6). At present, the large group of MAGE tumor antigens consists of $\sim 60$ proteins. Their specific expression in the majority of malignancies, coupled with their immunogenicity, makes these proteins promising targets for anticancer therapies (7). However, little is known about the function of MAGE-A tumor antigens. Studies by Doyle et al (8) and Yang et al (9) demonstrated the negative effect of MAGE expression on p53 levels. Notably, studies by Ries et al $(10,11)$ provided clear evidence that MAGE-A expression serves as predictor of malignant transformation in oral leukoplakia. Furthermore, there is evidence that MAGE-A is expressed in dysplastic leukoplakia and carcinoma in situ, but not in oral lichen planus, oral ulcers or leukoplakia without dysplasia (12). Another study revealed that MAGE-A tumor antigens are the most frequently expressed CTAs in head and neck cancer (13). Notably, there is no correlation between MAGE-A expression and clinicopathological characteristics in head and neck cancer. Recently, Laban et al (14) published data indicating a marked correlation between poor prognosis in a subset of patients with head and neck cancer and the expression of MAGE-A antigens. In addition, a previous study by our group identified a correlation between MAGE-A5 and -A8 expression and poorer responses to anti-epidermal growth factor receptor (EGFR) therapy in vitro (15). Of note, MAGE-A11 expression is also correlated with poorer responses to cisplatin, 5-fluorouracil, docetaxel and paclitaxel (16).

In head and neck cancer, targeted therapy has an expanding role. This therapeutic approach is largely based on the EGFR and its associated pathways. Downstream signaling molecules of the EGFR, mediate the invasion, growth, progression and survival of tumor cells (17). The majority of head and neck cancer specimens demonstrate overexpression of the EGFR, and alterations in the copy number of this receptor are associated with poor prognosis (18). In general, EGFR-targeted therapies 
for head and neck cancer are performed with cetuximab, a chimeric antibody directed against the EGFR. Targeting the EGFR by tyrosine kinase inhibitors is another well-studied field of oncology, particularly in the case of EGFR-mutated non-small cell lung cancer (NSCLC), in which erlotinib and gefitinib serve as useful drugs that aid the improvement of progression-free survival and overall survival (19). Unfortunately, in an unselected cohort of head and neck cancer patients, erlotinib failed to improve progression-free survival when used in combination with cisplatin and radiotherapy (20). The role of erlotinib in head and neck cancer may be more efficacious in the field of chemoprevention. Using a combined approach of erlotinib and sulindac, data from Shin et al (21) demonstrated effective chemoprevention in preclinical and clinical models. These findings are discussed in a study recently published by Gross et al (22).

The present study therefore aimed to investigate whether the expression of MAGE-A tumor antigens was associated with poor efficacy of erlotinib and gefitinib.

\section{Materials and methods}

Cell lines. The cell lines used in the present study (Table I) were established at the Cancer Institute of the University of Pittsburgh (Pittsburgh, PA, USA) (23). As described previously $(15,24)$, the cells were cultured in a humidified atmosphere of $5 \% \mathrm{CO}_{2} / 95 \%$ air at $37^{\circ} \mathrm{C}$ and were fed 2-3 times per week with Dulbecco's Modified Eagle's Medium (DMEM; Life Technologies, GmbH, Darmstadt, Germany) with low glucose, $10 \%$ fetal calf serum (Life Technologies, $\mathrm{GmbH}$ ), $1 \%$ penicillin/streptomycin (Life Technologies, $\mathrm{GmbH}$ ) and $1 \%$ L-glutamine (Biochrom KG, Berlin, Germany).

$R N A$ isolation and reverse transcription-quantitative polymerase chain reaction $(R T-q P C R)$ analysis of $M A G E-A$. The protocol and quantification of MAGE-A expression by RT-qPCR was conducted as previously described by our group $(15,16)$.

RNA isolation was executed using the NucleoSpin RNA II kit (Macherey-Nagel, Düren, Germany), according to the manufacturer's instructions. Isolated RNA was stored at $-80^{\circ} \mathrm{C}$ prior to reverse transcription. Complementary (c)DNA was synthesized from identical quantities of total RNA $(1 \mu \mathrm{g})$ with the M-MLV RT RNase H(-) point mutant using the buffer system provided (Promega Corp., Mannheim, Germany), according to the manufacturer's instructions.

MAGE-A expression profiles were quantitatively analyzed by RT-qPCR using the FastStart DNA Master Plus SYBR-Green I (Roche Diagnostics GmbH, Mannheim, Germany). Each reaction mixture $(20 \mu \mathrm{l})$ was comprised of $0.5 \mu \mathrm{l}$ cDNA, $1 \mu \mathrm{l}$ forward primer $(20 \mu \mathrm{M}), 1 \mu \mathrm{l}$ reverse primer $(20 \mu \mathrm{M})$ (both from TIB MOLBIOL GmbH, Berlin, Germany), $4 \mu$ l LightCycler DNA Master SYBR-Green I, $1 \mu 1$ dimethyl sulfoxide (Sigma-Aldrich, St. Louis, MO, USA) and $12.5 \mu \mathrm{l}$ water. The cycling conditions for RT-qPCR in the LightCycler 2.0 (Roche Diagnostics, Mannheim, Germany) were as follows: Initial denaturation at $95^{\circ} \mathrm{C}$ for $10 \mathrm{~min}$, followed by 45 cycles of amplification with denaturation at $95^{\circ} \mathrm{C}$ for $10 \mathrm{sec}$, primer annealing at $62-67^{\circ} \mathrm{C}$ for $3-4 \mathrm{sec}$ and elongation at $68-72^{\circ} \mathrm{C}$ for $3-4 \mathrm{sec}$ (specific temperature and elongation indicated in Table II). Following completion of this protocol, a melting range analysis was conducted. The protocol comprised one cycle at $95^{\circ} \mathrm{C}$ for $20 \mathrm{sec}$, followed by one cycle at $60^{\circ} \mathrm{C}$ for $20 \mathrm{sec}$ with continuously measured fluorescence. The values measured were analyzed by the LightCycler Relative Quantification Software 1.0 (Roche Diagnostics GmbH), which provided efficiency-corrected, calibrator-normalized relative quantification results. The relative concentrations were normalized to $\beta$-actin messenger RNA levels.

Drug treatment and crystal violet assay. Cells of each cell line were seeded at 10,000 cells/well, respectively. Erlotinib and gefitinib were purchased from Selleckchem (distributed by Absource Diagnostics GmbH, München, Germany) and stored according to the manufacturer's instructions. The concentrations used in the present study $(4.94,1.65,0.55,0.18$ and $0.06 \mu \mathrm{M})$ were derived from a $\log 3$ dilution starting at $400 \mu \mathrm{M}$ (data not shown). The control cells were cultured in medium as described above (without TKIs). These concentrations were chosen based on the clinically relevant maximum serum concentration of the selected tyrosine kinase inhibitors (TKIs), of $\sim 1 \mu \mathrm{M}$ (25). Following $24 \mathrm{~h}$ of incubation in standard medium, erlotinib or gefitinib was added, and the cultures were incubated for a further $72 \mathrm{~h}$. Crystal violet (1 g; Carl Roth $\mathrm{GmbH}$, Karlruhe, Germany) was dissolved in 11 double-distilled water containing $20 \%$ methanol. Following the removal of the drug-containing medium, $50 \mu \mathrm{l}$ crystal violet was added to each well and incubated for $15 \mathrm{~min}$. The 96-well plates were then washed with distilled water and the optical density (OD) was measured at $595 \mathrm{~nm}$ using a RainBow microplate reader (Tecan, Maennedorf, Swiss). All experiments were performed in triplicate. The mean was calculated from at least three independent experiments and used in further analyses.

Statistical analysis. The association between chemosensitivity and MAGE-A expression status was analyzed using a linear regression model. This model allows evaluation of the correlation between the viable fraction of the cell culture and the concentration of the drug, as well as the expression level of MAGE-A subgroups during drug treatment. However, since the linear regression model based on 6 MAGE-A subgroups is only able to include 4 possible variables, MAGE-A1 and -A9 were excluded by SPSS. P $\leq 0.05$ was considered to indicate a statistically significant difference. Statistical analysis of the data was performed using Microsoft Excel 2010 (Microsoft, Redmond, WA, USA) and SPSS Statistics 22 (IBM SPSS, Armonk, NY, USA) and was supported by the Department of Statistics, University of Würzburg. GraphPad Prism 6.04 (GraphPad Software Inc., La Jolla, CA, USA) was used to generate graphical illustrations.

\section{Results}

MAGE-A expression varies between squamous cell carcinoma cell lines. MAGE-A expression was detected in all five of the cell lines. The minimum number of expressed subgroups was two (in PCI-68). The lowest quantities of MAGE-A tumor antigens were also detected in PCI-68. In contrast to PCI-68, all MAGE-A tumor antigen subgroups examined were expressed by PCI-52. 
Table I. Name, origin and TNM status of the five cell lines used in the present study.

\begin{tabular}{llll}
\hline Cell line & \multicolumn{1}{c}{ Origin } & Patient gender & TNM \\
\hline PCI-1 & Laryngeal carcinoma of the glottis & male & pT2N00M0G2 \\
PCI-9 & Primary carcinoma at the base of the tongue & male & pT4N3M0G2 \\
PCI-13 & Oral squamous cell carcinoma of the retromolar triangle & male & pT4pN1M0G3 \\
PCI-52 & Primary carcinoma of the aryepiglottic fold & male & pT2N0M0G2 \\
PCI-68 & Primary tongue carcinoma & male & pT4N0M0G1 \\
\hline
\end{tabular}

Table II. Sequences, base pair lengths, annealing temperatures and elongation times of the primers used.

\begin{tabular}{|c|c|c|c|c|}
\hline Gene & Sequence, 5'-3' & Base pairs & Annealing, ${ }^{\circ} \mathrm{C} / \mathrm{sec}$ & Elongation, ${ }^{\circ} \mathrm{C} / \mathrm{sec}$ \\
\hline$\beta$-actin & $\begin{array}{l}\text { F: CCAACCGCGAGAAGATGA } \\
\text { R: CCAGAGGCGTACAGGGATAG }\end{array}$ & 97 & $65 / 3$ & $68 / 4$ \\
\hline MAGE-A1 & $\begin{array}{l}\text { F: GGCCGAAGGAACCTGACC } \\
\text { R: GTCCTCTGGGTTGGCCTGT }\end{array}$ & 69 & $67 / 3$ & $72 / 4$ \\
\hline MAGE-A5 & $\begin{array}{l}\text { F: GCCCTAGAGGAGCACCAAAG } \\
\text { R: CGCAACAGGCAGGAGTGT }\end{array}$ & 80 & $62 / 4$ & $72 / 3$ \\
\hline MAGE-A8 & $\begin{array}{l}\text { F: AAAGGTTCGCAGAGAACAGG } \\
\text { R: GTCAGGGCAGCAGGAGAGT }\end{array}$ & 119 & $65 / 3$ & $72 / 3$ \\
\hline MAGE-A9 & $\begin{array}{l}\text { F: GGCCTTGGTCTGAGACAGTG } \\
\text { R: GTCCTCCTGGTTAGCCTGT }\end{array}$ & 97 & $65 / 3$ & $72 / 3$ \\
\hline MAGE-A11 & $\begin{array}{l}\text { F: ACAGGAGTCCCAGGAGAACC } \\
\text { R: CTGTGGGAAATATCTGGGTGA }\end{array}$ & 81 & $67 / 3$ & $72 / 4$ \\
\hline MAGE-A12 & $\begin{array}{l}\text { F: GTCGGTGGAGGGAAGCAG } \\
\text { R: AGGGCAGCAGGTAGGAGTG }\end{array}$ & 104 & $65 / 3$ & $72 / 3$ \\
\hline
\end{tabular}

MAGE, melanoma-associated antigen; F, forward; R, reverse.

Furthermore, the highest expression of the subgroups -A1, -A9 and -A11 was also detected in PCI-52. The highest expression of MAGE-A5 was detected in PCI-9, while PCI-13 exhibited the highest levels of MAGE-A8, and the greatest expression of MAGE-A12 was identified in the PCI-1 cell line (Fig. 1).

Efficacy of erlotinib treatment varies between squamous cell carcinoma cell lines. Four of the five cell lines (PCI-1, PCI-9, PCI-13 and PCI-68) exhibited a concentration-dependent response to $72 \mathrm{~h}$ of erlotinib treatment (Fig. 1). At the minimum concentration of $0.06 \mu \mathrm{M}$, the fraction of viable cells ranged from 69.51 (PCI-1) to $91.71 \%$ (PCI-68), compared with that of the control. The intermediate concentration $(0.55 \mu \mathrm{M})$ of erlotinib resulted in a viable fraction of $54.07 \%$ in the PCI-1 cell line, whereas this concentration resulted in a viable fraction of $83.93 \%$ in PCI-9 cells. The maximum concentration of erlotinib $(4.94 \mu \mathrm{M})$ resulted in a viable fraction of $42.15 \%$ in PCI-1 cells, while in PCI-9 cells, this concentration resulted in a viable fraction of $74.90 \%$. By contrast, the PCI-52 cell line demonstrated no concentration-dependent response to erlotinib. Erlotinib concentrations of $0.06,0.18,0.55$ and $1.65 \mu \mathrm{M}$ yielded no significant effect on viability (resulting in 102.78, $102.85,101.14$ and $102.60 \%$, respectively). Only the highest concentration of $4.94 \mu \mathrm{M}$ erlotinib resulted in a small decrease in viability compared with that of the control (94.03\%).
Erlotinib treatment efficacy is affected by MAGE-A expression. A linear regression model was produced using erlotinib concentration and MAGE-A expression levels as independent variables (Table III), with the viable fraction compared with the control as the dependent variable. The model produced an r-value of 0.848 , indicating a notable adaptation. MAGE-A1 and -A9 were excluded as independent variables. However, potential effects of MAGE-A1 and -A9 may be determined using a larger regression model with more cell lines. Negative values of the standardized coefficients represent an inhibitory effect on the fraction of viable cells. By contrast, positive values of the standardized coefficients indicate a beneficial effect on the fraction of viable cells. Increasing concentrations of erlotinib significantly decreased the viability of cells $(\mathrm{P}<0.001)$. MAGE-A12 was also associated with a decrease in the viable fraction during erlotinib treatment $(\mathrm{P}=0.009)$, while MAGE-A5 $(\mathrm{P}=0.015)$ and $-\mathrm{A} 11(\mathrm{P}<0.001)$ were correlated with a higher fraction of viable cells following erlotinib treatment.

Efficacy of gefitinib treatment varies between squamous cell carcinoma cell lines. Analogously with the results described for erlotinib treatment, four of the five cell lines (PCI-1, PCI-9, PCI-13 and PCI-68) exhibited a concentration-dependent response to $72 \mathrm{~h}$ of gefitinib treatment (Fig. 1). The minimum concentration of $0.06 \mu \mathrm{M}$ resulted in cell viabilities of $57.56 \%$ in PCI-1, 

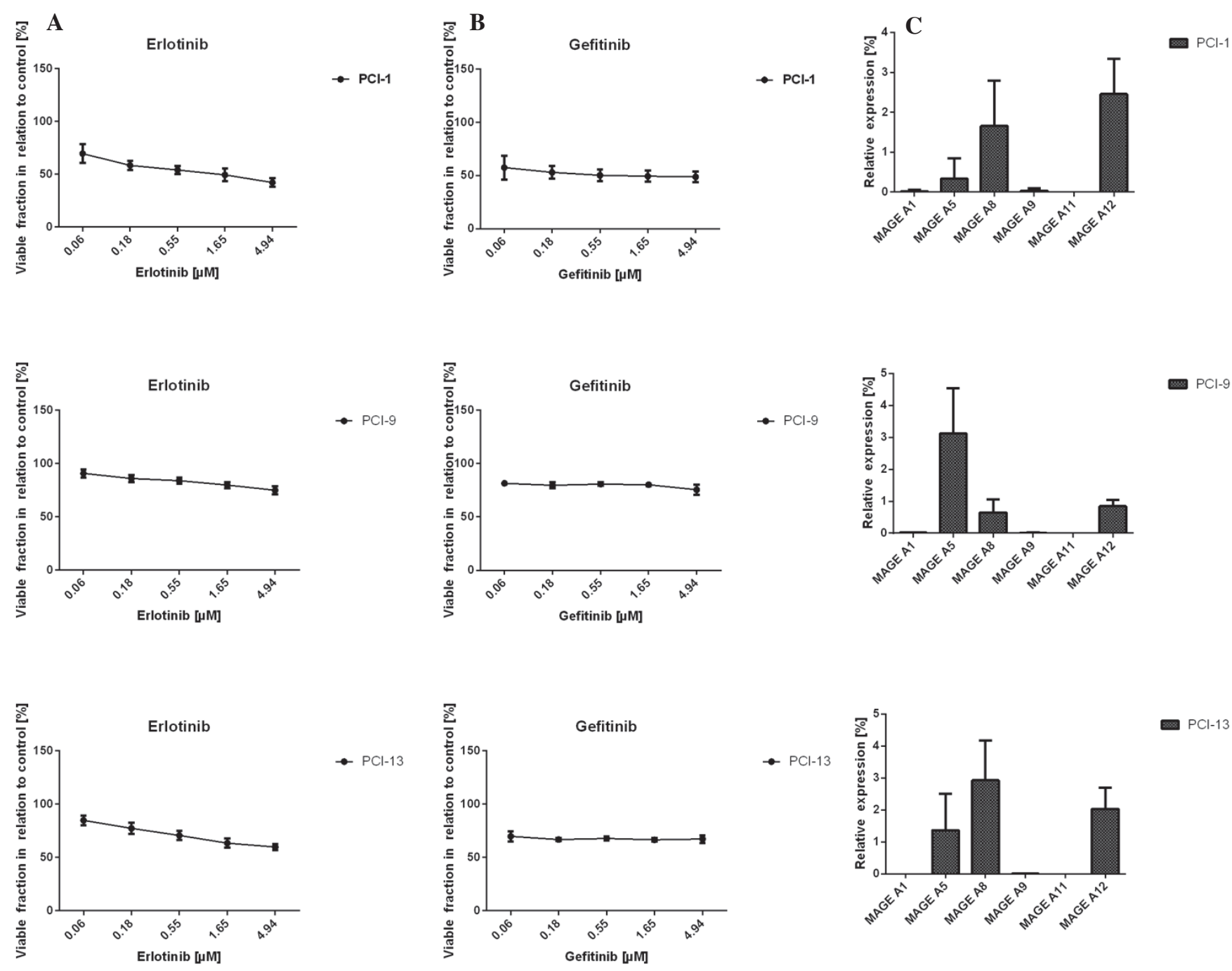

미미 $\mathrm{PCl}$
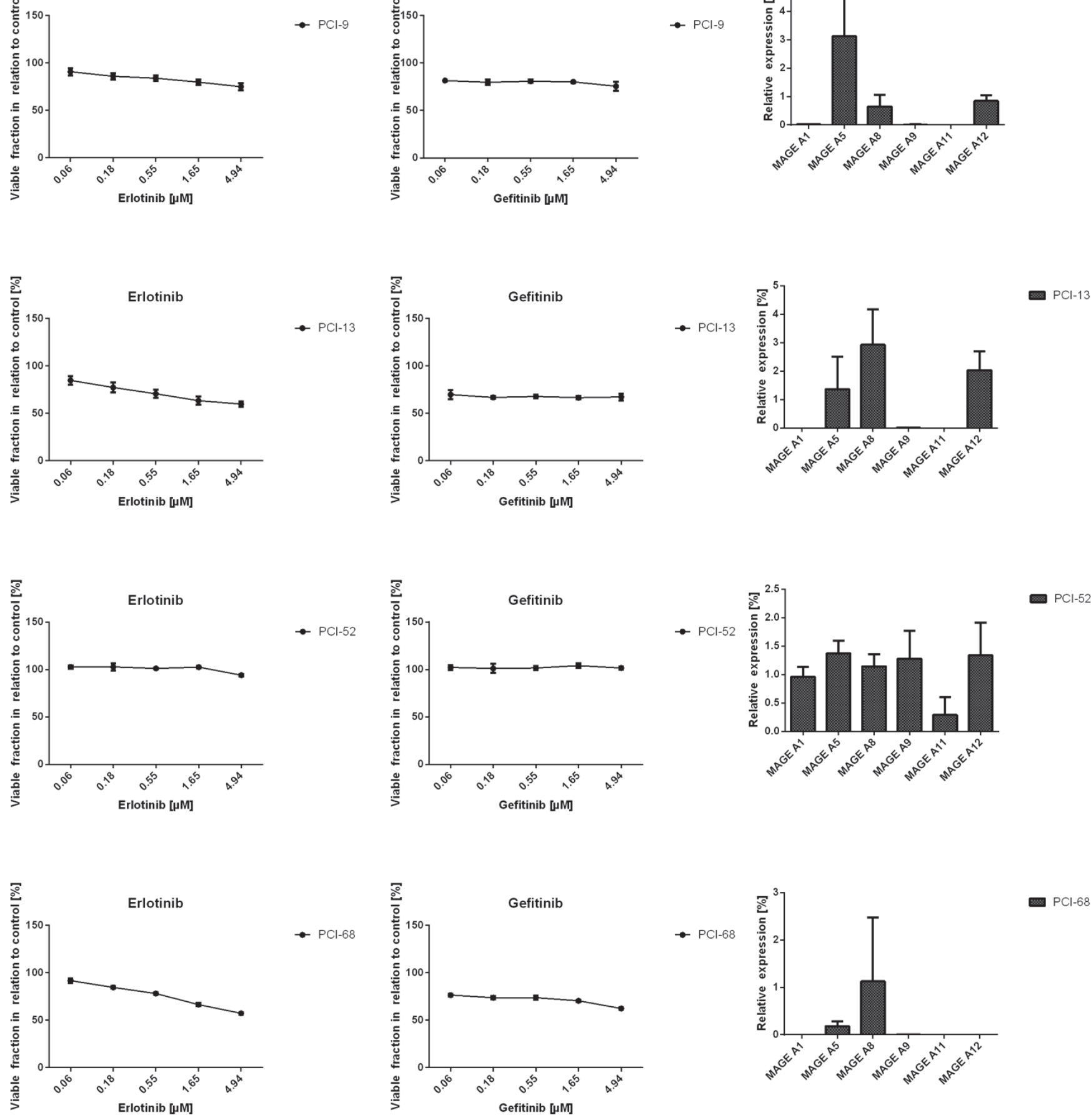

Figure 1. Effects of erlotinib and gefitinib on cell viability and MAGE-A subgroup expression profiles of head and neck squamous cell carcinoma cell lines. Fraction of viable cells compared with that of the control (100\%) following $72 \mathrm{~h}$ of (A) erlotinib or (B) gefitinib treatment. With the exception of the PCI-52 cell line, all cell lines demonstrated a marked decrease in viable cells following drug treatment. Standard deviation is illustrated by error bars extending above and below the data points. (C) Cell-specific MAGE-A subgroup expression profile of each cell line, relative to $\beta$-actin expression. MAGE, melanoma-associated antigen. 
Table III. Linear regression of erlotinib/MAGE-A subgroup following $72 \mathrm{~h}$ of treatment.

\begin{tabular}{lcr}
\hline $\begin{array}{l}\text { Independent } \\
\text { variable }\end{array}$ & $\begin{array}{c}\text { Standardized } \\
\text { coefficient }\end{array}$ & P-value \\
\hline MAGE-A5 & $\mathbf{0 . 2 9 9}$ & $\mathbf{0 . 0 1 5}$ \\
MAGE-A8 & 0.168 & 0.274 \\
MAGE-A11 & $\mathbf{0 . 5 7 4}$ & $<\mathbf{0 . 0 0 1}$ \\
MAGE-A12 & $\mathbf{- 0 . 3 9 8}$ & $\mathbf{0 . 0 0 9}$ \\
Erlotinib concentration & $\mathbf{- 0 . 4 8 2}$ & $<\mathbf{0 . 0 0 1}$ \\
\hline
\end{tabular}

Bold text indicates statistically significant results. MAGE, melanomaassociated antigen.

$81.57 \%$ in PCI-9, 69.77\% in PCI-13 and $76.38 \%$ in PCI-68 cells, indicating a markedly greater efficacy of gefitinib than that of the lowest concentration of erlotinib. At the intermediate concentration $(0.55 \mu \mathrm{M})$ of gefitinib, the fraction of viable cells ranged from $50.34 \%$ in PCI-1 cells to $80.87 \%$ in PCI-9 cells. Compared with the control, the maximum concentration of $4.94 \mu \mathrm{M}$ gefitinib resulted in viable fractions of 48.87 and $75.51 \%$ in PCI-1 and PCI-9 cells, respectively. Notably, compared with the lowest concentration of erlotinib, gefitinib produced greater responses in the PCI-1, PCI-9, PCI-13 and PCI-68 cell lines. Conversely, erlotinib treatment at the intermediate and highest concentrations yielded better results than those of gefitinib. As previously observed following erlotinib treatment, PCI-52 did not demonstrate a concentration-dependent response to gefitinib treatment. Furthermore, even the highest concentration of gefitinib $(4.94 \mu \mathrm{M})$ failed to reduce cell viability compared with that of the control (101.59\%).

Gefitinib treatment efficacy is affected by MAGE-A expression. The linear regression model was constructed using the gefitinib concentration and MAGE-A expression levels as independent variables (Table IV), with the viable fraction compared with the control as the dependent variable. The model generated an r-value of 0.805 . Analogously to the results obtained in the analysis of erlotinib, negative standardized coefficient values represented an inhibitory effect on the fraction of viable cells, while positive values indicated a beneficial effect on the fraction of viable cells. The increasing concentration of gefitinib significantly reduced the fraction of viable cells $(\mathrm{P}=0.046)$, demonstrating a concentration-dependent response of the cell lines to gefitinib treatment (Table IV). MAGE-A12 was also associated with a decreased number of viable cells following gefitinib treatment $(\mathrm{P}=0.027)$. Cell lines expressing MAGE-A11 demonstrated the lowest response to gefitinib treatment, as indicated by the large fraction of viable cells $(\mathrm{P}<0.001)$. MAGE-A5 expression was also correlated with a significantly poorer efficacy of gefitinib treatment $(\mathrm{P}=0.028)$, while MAGE-A8 expression did not significantly alter the fraction of viable cells $(\mathrm{P}=0.364)$. MAGE-A1 and -A9 were again excluded as independent variables.

\section{Discussion}

Due to the high rate of recurrence and a poor overall survival rate of $\sim 50 \%$, the treatment of head and neck squamous
Table IV. Linear regression of gefitinib/MAGE-A subgroup following $72 \mathrm{~h}$ of treatment.

\begin{tabular}{lcr}
\hline $\begin{array}{l}\text { Independent } \\
\text { variable }\end{array}$ & $\begin{array}{c}\text { Standardized } \\
\text { coefficient }\end{array}$ & P-value \\
\hline MAGE-A5 & $\mathbf{0 . 3 0 0}$ & $\mathbf{0 . 0 2 8}$ \\
MAGE-A8 & 0.156 & 0.364 \\
MAGE-A11 & $\mathbf{0 . 6 6 1}$ & $<\mathbf{0 . 0 0 1}$ \\
MAGE-A12 & $\mathbf{- 0 . 3 7 1}$ & $\mathbf{0 . 0 2 7}$ \\
Gefitinib concentration & $\mathbf{- 0 . 2 5 5}$ & $\mathbf{0 . 0 4 6}$ \\
\hline
\end{tabular}

Bold text indicates statistically significant results. MAGE, melanomaassociated antigen.

cell carcinoma (HNSCC) remains challenging. Therefore, improvements to patient selection in terms of non-surgical treatment approaches may help to enhance clinical outcomes. One technique for the identification of high-risk patients may be via the evaluation of MAGE-A expression status. There is an increasing understanding that the expression of certain CTAs, including MAGE-A, is associated with markedly poorer survival amongst patients with head and neck cancer (14). The present study revealed inhomogeneous expression of MAGE-A1, -A5, -A8, -A9, -A11 and -A12 in the HNSCC cell lines tested. Furthermore, treatment with erlotinib and gefitinib at clinically relevant concentrations yielded differential response rates in the various HNSCC cell lines. While four of the five cell lines (PCI-1, PCI-9, PCI-13 and PCI-68) exhibited concentration-dependent responses to erlotinib and gefitinib, TKI treatment of PCI-52 cells was completely ineffective. The PCI-1 and PCI-52 cell lines were comparable in terms of their TNM status; however, PCI-52 was the only cell line to express all of the MAGE-A subgroups investigated, while PCI-1 expressed three out of the six subgroups. Notably, the PCI-1 cell line was the most responsive to erlotinib and gefitinib treatment, whereas PCI-52 was entirely resistant to these two agents. These results highlight an urgent need for the identification of additional molecular markers, including MAGE-A tumor antigens.

The linear regression models of erlotinib and gefitinib revealed marked adaptation (r-values, 0.848 and 0.805 , respectively) and significant effects of agent concentration on the fraction of viable cells, providing evidence for a useful experimental setup. Correlation analysis of MAGE-A subgroups and erlotinib treatment revealed MAGE-A5 and -A11 as significant negative predictors of treatment success. Of note, MAGE-A11 was previously shown to act as a proto-oncogene in prostate cancer by serving as a transcriptional activator of the androgen receptor (26). By contrast, MAGE-A12 was associated with an improved outcome of erlotinib administration. In a previous study by our group, MAGE-A5 and -A8 were reported as negative predictors of anti-EGFR therapy using panitumumab (15). In agreement with a recent study by our group, MAGE-A12 was correlated with a greater response to panitumumab (15). Mollaoglu et al (27) previously described MAGE-A12 as a predictor of improved prognosis in oral squamous cell carcinoma. As described by their group, NO cervical lymph node 
status was found more frequently in MAGE-A12-positive patients than that of the MAGE-negative controls. Furthermore, MAGA-A11 was reported to have a negative impact on treatment with cisplatin, 5-fluorouracil, paclitaxel and docetaxel (16). In the same study, MAGE-A5 was demonstrated to be associated with improved outcomes following paclitaxel therapy. Statistical analysis revealed that treatment with gefitnib or erlotinib were comparable in the context of MAGE-A expression. MAGE-A5 and -A11 were correlated with poorer outcomes of gefitinib therapy. Similarly to the effects observed following erlotinib treatment, improved outcomes of gefitinib treatment were associated with MAGE-A12 expression. A potential reason for the negative influence of MAGE-A11 on EGFR-directed therapies may be due to its association with the expression of other transmembrane receptors. Recently, Hou et al (28) demonstrated a significant correlation between MAGE-A9 and -A11 expression and Her2/neu expression in breast cancer. There is a broad consensus that evasion of EGFR-targeted therapy is facilitated by the activation of alternative receptors, including Her2/neu, as well as their downstream signaling pathways $(29,30)$. Even if TKI treatment combined with cisplatin and radiotherapy failed to improve progression-free survival in unselected cohorts, erlotinib and gefitinib may function as chemopreventive drugs (31). One significant consideration in the treatment of patients with head and neck cancer is the phenomenon of field cancerization (32). Therefore, the possibility of reducing the incidence of malignant transformation to dysplastic oral mucosa may be a valuable tool, based on the findings regarding the chemoproventative properties of TKIs $(31,32)$. MAGE-A subgroup analysis may help to identify high-risk patients, thus aiding the development of personalized therapies and follow-up.

\section{Acknowledgements}

The present study was funded by the Interdisciplinary Center for Clinical Research of the University of Würzburg (grant no. Z-3/13). The manuscript was spell-checked by the American Journal Experts (Durham, NC, USA).

\section{References}

1. van der Bruggen $\mathrm{P}$, Traversari C, Chomez P, Lurquin C, De Plaen E, Van den Eynde BJ, Knuth A and Boon T: A gene encoding an antigen recognized by cytolytic $\mathrm{T}$ lymphocytes on a human melanoma. J Immunol 178: 2617-2621, 2007.

2. Old LJ and Chen YT: New paths in human cancer serology. J Exp Med 187: 1163-1167, 1998.

3. Kienstra MA, Neel HB, Strome SE and Roche P: Identification of NY-ESO-1, MAGE-1, and MAGE-3 in head and neck squamous cell carcinoma. Head Neck 25: 457-463, 2003.

4. Müller-Richter UD, Dowejko A, Zhou W, Reichert TE and Driemel O: Different expression of MAGE-A-antigens in foetal and adult keratinocyte cell lines. Oral Oncol 44: 628-633, 2008.

5. Scanlan MJ, Simpson AJ and Old LJ: The cancer/testis genes: Review, standardization, and commentary. Cancer Immun 4: 1, 2004.

6. Simpson AJ, Caballero OL, Jungbluth A, Chen YT and Old LJ: Cancer/testis antigens, gametogenesis and cancer. Nat Rev Cancer 5: 615-625, 2005.

7. Ferris RL: Progress in head and neck cancer immunotherapy: Can tolerance and immune suppression be reversed? ORL J Otorhinolaryngol Relat Spec 66: 332-340, 2004.

8. Doyle JM, Gao J, Wang J, Yang M and Potts PR: MAGE-RING protein complexes comprise a family of E3 ubiquitin ligases. Mol Cell 39: 963-974, 2010.
9. Yang B, O'Herrin SM, Wu J, Reagan-Shaw S, Ma Y, Bhat KM Gravekamp C, Setaluri V, Peters N, Hoffmann FM, et al: MAGE-A, mMage-b, and MAGE-C proteins form complexes with KAP1 and suppress p53-dependent apoptosis in MAGE-positive cell lines. Cancer Res 67: 9954-9962, 2007.

10. Ries J, Agaimy A, Vairaktaris E, Gorecki P, Neukam FW, Strassburg LH and Nkenke E: Detection of MAGE-A expression predicts malignant transformation of oral leukoplakia. Cancer Invest 30: 495-502, 2012.

11. Ries J, Agaimy A, Vairaktaris E, Kwon Y, Neukam FW, Strassburg LH and Nkenke E: Evaluation of MAGE-A expression and grade of dysplasia for predicting malignant progression of oral leukoplakia. Int J Oncol 41: 1085-1093, 2012.

12. Krauss E, Rauthe S, Gattenlöhner S, Reuther T,Kochel M,Kriegebaum U, Kübler AC and Müller-Richter UD: MAGE-A antigens in lesions of the oral mucosa. Clin Oral Investig 15: 315-320, 2011

13. Piotti KC, Scognamiglio T, Chiu R and Chen YT: Expression of cancer/testis (CT) antigens in squamous cell carcinoma of the head and neck: Evaluation as markers of squamous dysplasia. Pathol Res Pract 209: 721-726, 2013.

14. Laban S, Atanackovic D, Luetkens T, Knecht R, Busch CJ Freytag M, Spagnoli G, Ritter G, Hoffmann TK, Knuth A, et al: Simultaneous cytoplasmic and nuclear protein expression of melanoma antigen-A family and NY-ESO-1 cancer-testis antigens represents an independent marker for poor survival in head and neck cancer. Int J Cancer 135: 1142-1152, 2014.

15. Hartmann S, Kriegebaum U, Küchler N, Lessner G, Brands RC, Linz C, Schneider T, Kübler AC and Müller-Richter UD: Efficacy of cetuximab and panitumumab in oral squamous cell carcinoma cell lines: Prognostic value of MAGE-A subgroups for treatment success. J Craniomaxillofac Surg 41: 623-629, 2013.

16. Hartmann S, Kriegebaum U, Küchler N, Brands RC, Linz C, Kübler AC and Müller-Richter UD: Correlation of MAGE-A tumor antigens and the efficacy of various chemotherapeutic agents in head and neck carcinoma cells. Clin Oral Investig 18: 189-197, 2014.

17. Yarden Y and Shilo BZ: SnapShot: EGFR signaling pathway. Cell 131: 1018, 2007

18. Temam S, Kawaguchi H, El-Naggar AK, Jelinek J, Tang H, Liu DD, Lang W, Issa JP, Lee JJ and Mao L: Epidermal growth factor receptor copy number alterations correlate with poor clinical outcome in patients with head and neck squamous cancer. J Clin Oncol 25: 2164-2170, 2007.

19. Asami K and Atagi S: Epidermal growth factor receptor tyrosine kinase inhibitors for non-small cell lung cancer. World J Clin Oncol 5: 646-659, 2014.

20. Martins RG, Parvathaneni U, Bauman JE, Sharma AK, Raez LE, Papagikos MA, Yunus F, Kurland BF, Eaton KD, Liao JJ, et al: Cisplatin and radiotherapy with or without erlotinib in locally advanced squamous cell carcinoma of the head and neck: A randomized phase II trial. J Clin Oncol 31: 1415-1421, 2013.

21. Shin DM, Zhang H, Saba NF, Chen AY, Nannapaneni S, Amin AR, Müller S, Lewis M, Sica G, Kono S, et al: Chemoprevention of head and neck cancer by simultaneous blocking of epidermal growth factor receptor and cyclooxygenase- 2 signaling pathways: Preclinical and clinical studies. Clin Cancer Res 19: 1244-1256, 2013.

22. Gross ND, Bauman JE, Gooding WE, Denq W, Thomas SM, Wang L, Chiosea S, Hood BL, Flint MS, Sun M, et al: Erlotinib, erlotinib-sulindac versus placebo: A randomized, double-blind, placebo-controlled window trial in operable head and neck cancer. Clin Cancer Res 20: 3289-3298, 2014.

23. Heo DS, Snyderman C, Gollin SM, Pan S, Walker E, Deka R, Barnes EL, Johnson JT, Herberman RB and Whiteside TL: Biology, cytogenetics, and sensitivity to immunological effector cells of new head and neck squamous cell carcinoma lines. Cancer Res 49: 5167-5175, 1989.

24. Hartmann S, Seher A, Brands RC, Linz C, Lessner G, Böhm H, Kübler AC and Müller-Richter UD: Influence of epidermal growth factor receptor expression on the cetuximab and panitumumab response rates of head and neck carcinoma cells. J Craniomaxillofac Surg 42: 1322-1328, 2014.

25. Mukohara T, Engelman JA, Hanna NH, Yeap BY, Kobayashi S, Lindeman N, Halmos B, Pearlberg J, Tsuchihashi Z, Cantley LC, et al: Differential effects of gefitinib and cetuximab on non-small-cell lung cancers bearing epidermal growth factor receptor mutations. J Natl Cancer Inst 97: 1185-1194, 2005.

26. Su S, Minges JT, Grossman G, Blackwelder AJ, Mohler JL and Wilson EM: Proto-oncogene activity of melanoma antigen-A11 (MAGE-A11) regulates retinoblastoma-related p107 and E2F1 proteins. J Biol Chem 288: 24809-24824, 2013. 
27. Mollaoglu N, Vairaktaris E, Nkenke E, Neukam FW and Ries J: Expression of MAGE-A12 in oral squamous cell carcinoma. Dis Markers 24: 27-32, 2008

28. Hou SY, Sang MX, Geng CZ, Liu WH, Lü WH, Xu YY and Shan BE: Expressions of MAGE-A9 and MAGE-A11 in breast cancer and their expression mechanism. Arch Med Res 45: 44-51, 2014.

29. Quesnelle KM and Grandis JR: Dual kinase inhibition of EGFR and HER2 overcomes resistance to cetuximab in a novel in vivo model of acquired cetuximab resistance. Clin Cancer Res 17: 5935-5944, 2011.

30. Yonesaka K, Zejnullahu K, Okamoto I, Satoh T, Cappuzzo F, Souglakos J, Ercan D, Rogers A, Roncalli M, Takeda M, et al: Activation of ERBB2 signaling causes resistance to the EGFR-directed therapeutic antibody cetuximab. Sci Transl Med 3: 99ra86, 2011.
31. Rosenthal EL, Chung TK, Carroll WR, Clemons L, Desmond R and Nabell L: Assessment of erlotinib as adjuvant chemoprevention in high-risk head and neck cancer patients. Ann Surg Oncol 21: 4263-4269, 2014.

32. Jaiswal G, Jaiswal S, Kumar R and Sharma A: Field cancerization: Concept and clinical implications in head and neck squamous cell carcinoma. J Exp Ther Oncol 10: 209-214, 2013. 